\title{
Commentary: Past, present, and future of epigenetics applied to livestock breeding - Hard versus Soft Lamarckian Inheritance Mechanisms
}

\author{
Edward J. Steele * \\ CY O'Connor ERADE Village Foundation, Piara Waters, WA, Australia
}

Keywords: epigenetics, animal breeding, population genomics, sustainability, breeding programs, Lamarckian inheritance

\section{A commentary on}

Past, present, and future of epigenetics applied to livestock breeding

by González-Recio, O., Toro, M. A., and Bach, A. (2015). Front. Genet. 6:305. doi:

OPEN ACCESS

Edited by:

Peter Dovc

University of Ljubljana, Slovenia

Reviewed by:

Scott Newman,

Genus, plc, USA

Alex Clop,

Center for Research in Agricultural Genomics (CRAG), Spain

*Correspondence:

Edward J. Steele

ejsteele@cyo.edu.au

Specialty section:

This article was submitted to

Livestock Genomics,

a section of the journal

Frontiers in Genetics

Received: 17 October 2015 Accepted: 13 February 2016

Published: 23 February 2016

Citation:

Steele EJ (2016) Commentary: Past, present, and future of epigenetics applied to livestock breeding - Hard versus Soft Lamarckian Inheritance Mechanisms. Front. Genet. 7:29. doi: 10.3389/fgene.2016.00029 10.3389/fgene.2015.00305

The article by González-Recio et al. (2015) claims to "review the concept of Lamarckian inheritance and the use of the term epigenetics in the field of animal genetics." I began reading with interest as I am involved in selective livestock improvement (Williamson et al., 2011) using the ancestral haplotype approach to establish associations with desirable beef quality traits (Dawkins, 2015). I was curious where the epigenetics field was situated in this regard. However, in the introductory section, "The Old Ideas," I considered their comments on an earlier book of mine (Steele et al., 1998) were incorrect. Further, the rest of their article had, in my view, a major omission on what constitutes Weismann's Doctrine and the Central Dogma of Molecular Biology (below). Having said this the review by Gonzalez-Recio et al is an otherwise thoughtful and informative article on the application of transgenerational epigenetic ideas and phenomena to livestock improvement. Indeed I have no argument with accurate recounting of the difficulties documenting "hard" epigenetic inheritance in mammals (the transmission of an epigenetic character beyond three generations).

Understanding the genetic rules for how a reversible (erasable and thus "soft") epigenetic trait can be made into a "hard" genetic transmission process involving modifications to germline DNA sequences, is a worthy research goal. Given the current state of immunological knowledge I am persuaded by the data that "hard" types of soma-to-germline transfer are ongoing at very high frequency in human immune system germlines, and, by extension, other mammalian germlines (below).

I have been developing Lamarckian soma-to-germline concepts and reverse transcriptase (RT) based feedback mechanisms-"hard" Lamarckian Inheritance-since 1978 (Steele, 1979, 2009a; Rothenfluh and Steele, 1993; Rothenfluh et al., 1995; Blanden et al., 1998; Steele et al., 1998; Zylstra et al., 2003; Steele and Lloyd, 2015). This research has run parallel to investigations on similar RT-based mechanisms in the antigen-driven somatic hypermutation (SHM) of rearranged immunoglobulin (Ig) variable genes, so called VDJs (Steele and Pollard, 1987; Blanden et al., 1998; Weiller et al., 1998; Franklin et al., 2004; Steele et al., 2006; Steele, 2009b). This has led to studies showing that RT-based strand-biased mutation mechanisms, and recently 


\section{A Central Dogma of Molecular Biology}

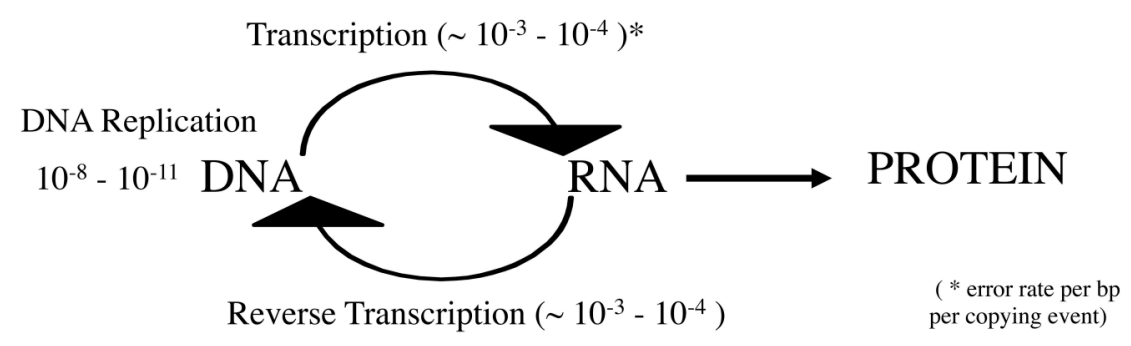

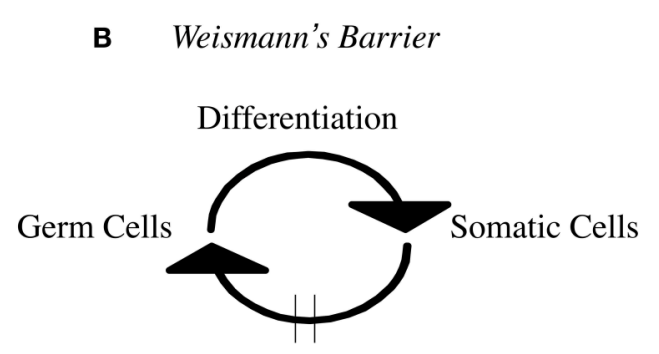

B

Weismann's Barrier

c

Weismann's Barrier

Semipermeable eg V genes

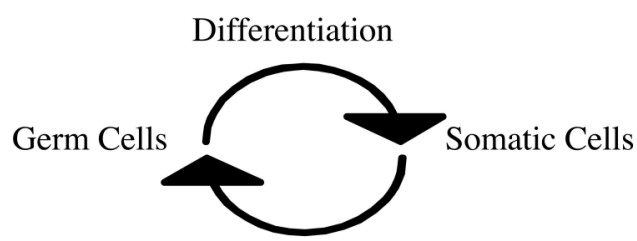

Soma-to-Germline Feedback

FIGURE 1 | (A) Central Dogma of Molecular Biology, (B) Weismann's Barrier, and (C) Weismann's Barrier is semipermeable eg V genes.

to Robyn Lindley's codon-contexted targeted mutagenesis, apply to dysregulated SHM as a general causal mechanism in all cancers (Steele and Lindley, 2010; Lindley, 2013; Lindley and Steele, 2013).

Given that reverse transcription is at the heart of any modern "hard" Lamarckian inheritance mechanism I was surprised that "reverse transcription" is not mentioned by Gonzalez-Recio et al. This is curious because the RNA to DNA step has been embodied in the Central Dogma of Molecular Biology since the discovery of reverse transcription by Temin and Mizutuni (1970) and Baltimore (1970). Crick, who like Temin anticipated it enshrined it in his famous "modification" of the Central Dogma in Nature in 1970 (Crick, 1970; summarized in Figure 1A).

Indeed the rigid dictum DNA-> RNA- $>$ Protein is the earlier 1960s rendition which is often mistakenly confused with Weismann's Doctrine (Figure 1B). It must be made clear that Weismann's Barrier enshrines a cellular theory of information flow whereas the Central Dogma is a theory of information flow at the molecular level. I found it necessary to draw these clear distinctions when the Somatic Selection Hypothesis was first formulated 37 years ago (Steele, 1979). In that theory the data were marshaled to advocate that for the immune system at least, Weismann's Barrier was selectively permeable to somatic immunoglobulin $\mathrm{V}$ gene mutants (Figure 1C).

I draw out these historical threads as they were not made clear in the Gonzalez-Recio et al article.

My primary reason for writing this invited Commentary is the statement by the authors: "In immunology, Steele et al. (1998) claimed that environment could make the immune system to change its DNA structure, and these changes could be transmitted to the offspring, assertions that have yet to be confirmed." Apart from anything else I might add our work ca. 1998 was more than just an "assertion," as it summarized 20 years of work and experimental data (note: "Basic Books" as mentioned in the authors' reference list were not the publishers of Lamarck's Signature in the US, it was Perseus Books).

Extensive DNA sequence data shows that the signature of antigen-driven somatic hypermutation of somatically rearranged VDJ genes is embedded within all vertebrate unrearranged germline V segment arrays examined (Rothenfluh et al., 1995; Blanden et al., 1998; Steele, 2009a; Steele and Lloyd, 2015). This striking fact requires a rational explanation-we have provided that explanation and this has never been challenged by molecular immunologists over the past 25 years (at least since our first published report on such patterns in Rothenfluh and Steele, 1993). The logic of this interpretation is outlined in our many papers and the 1998 book, Lamarck's Signature.

Certainly as Fogarty (2002) and the group of Corrado Spadafora have repeatedly shown (Zoraqi and Spadafora, 1997; Spadafora, 2008; Cossetti et al., 2014) there is no physical barrier preventing somatic RNA/DNA sequences entering the mammalian germline. Sperm developing in the epididymis are most susceptible to this uptake. The transfer of somatic regulatory miRNAs may well use the same soma-to-germline channel for epigenetic transfers in male mice (Rassoulzadegan et al., 2006). This is now emphatically underlined by the recent work of Oliver Rando and colleagues which clearly shows that "small RNA biogenesis and its dietary regulation during post-testicular sperm maturation" linking these "tRNA fragments to regulation of endogenous retroelements active in the preimplantation embryo" (Sharma et al., 2016). Thus vesicles identified as "epididymosomes" carrying RNA payloads matching 
those of mature sperm, clearly fuse with spermatozoa during epididymal transit and can also be shown to deliver these somatic RNAs to immature sperm in vitro (Sharma et al., 2016). What is lacking in all this is a reverse transcription step to lock in these somatic RNAs into germline DNA. Likely RT candidates are the Y family of DNA polymerases (eta, kappa, and iota) or LINE retroelement encoded reverse transcriptases (Franklin et al., 2004; Spadafora, 2008).

However, RNA-templated DNA repair is a generic process in Eukaryotes feeding RNA information back to DNA by conventional DNA polymerases. Thus there exists in the yeast Saccharomyces cerevisiae a default DNA repair pathway whereby normal DNA replication polymerases use short RNA templates (6-12 nt) to repair double strand breaks in a physiologically efficient manner (Storici et al., 2007).

Finally there is now a clear necessity to seriously consider nonmendelian soma-to-germline transfer modes. Individual human antibody $\mathrm{V}$ repertoire sequencing and V-D-J haplotype analyses are now showing that novel $\mathrm{V}$ genes are unexpectedly appearing at a very high rate in the human germline implying that such events happen prior to every sperm-embryo union [critically evaluated in Steele and Lloyd (2015) but see in particular Kidd et al. (2012) and Gadala-Maria et al. (2015)]. This striking realization throws down the gauntlet to develop more reliable and

\section{REFERENCES}

Baltimore, D. (1970). RNA-dependent DNA polymerase in virions of RNA tumor virus. Nature 26, 1209-1211. doi: 10.1038/2261209a0

Blanden, R. V., Rothenfluh, H. S., Zylstra, P., Weiller, G. F., and Steele, E. J. (1998). The signature of somatic hypermutation appears to be written into the germline IgV segment repertoire. Immunol. Rev. 162, 117-132. doi: 10.1111/j.1600065X.1998.tb01435.x

Cossetti, C., Lugini, L., Astrologo, L., Saggio, I., Fais, S., Spadafora, C., et al. (2014). Soma-to- germline transmission of RNA in mice xenografted with human tumour cells: possible transport by exosomes. PLoS ONE 9:e101629. doi: 10.1371/journal.pone.0101629

Crick, F. H. (1970). Central dogma of molecular biology. Nature 227, 561-563. doi: $10.1038 / 227561 \mathrm{a} 0$

Dawkins, R. L. (2015). Adapting Genetics: Quantal Evolution After Natural Selection - Surviving the Changes to Come. Dallas, TX: Nearurban Press.

Devanapally, S., Ravikumar, S., and Jose, A. M. (2015). Double-stranded RNA made in C. elegans neurons canenter the germline and cause transgenerational gene silencing. Proc. Natl Acad. Sci. U.S.A. 112, 2133-2138. doi: 10.1073/pnas. 1423333112

Fogarty, P. (2002). Optimizing the production of animal models for target and lead validation. Targets 1, 109-116. doi: 10.1016/S1477-3627(02)02198-0

Franklin, A., Milburn, P. J., Blanden, R. V., and Steele, E. J. (2004). Human DNA polymerase- $\eta$, an A-T mutator in somatic hypermutation of rearranged immunoglobulin genes, is a reverse transcriptase. Immunol. Cell Biol. 82, 219-225. doi: 10.1046/j.0818-9641.2004.01221.x

Gadala-Maria, D., Yaari, G., Uduman, M., and Kleinstein, S. H. (2015). Automated analysis of high-throughput B-cell sequencing data reveals a high frequency of novel immunoglobulin V gene segment alleles. Proc. Natl. Acad. Sci. U.S.A. 112, E862-E870. doi: 10.1073/pnas.1417683112

González-Recio, O., Toro, M. A., and Bach, A. (2015). Past, present, and future of epigenetics applied to livestock breeding. Front. Genet. 6:305. doi: 10.3389 /fgene.2015.00305

Gorczynski, R. M., and Steele, E. J. (1980). Inheritance of acquired immunologic tolerance to foreign histocompatibility antigens in mice. Proc. Natl. Acad. Sci. U.S.A. 77, 2871-2875. accurate long-read DNA sequencing so that complete haplotypes in the megabase range at the IGHV and IGHL loci-which contain highly similar V sequences-can be characterized by testing for putative haplotype segregation in three generation families (Steele and Lloyd, 2015).

\section{AUTHOR CONTRIBUTIONS}

The author confirms being the sole contributor of this work and approved it for publication.

\section{ACKNOWLEDGMENTS}

The author acknowledges CY O'Connor ERADE Village Foundation for support.

\section{NOTE ADDED IN PROOF}

The earlier demonstrations by the author of soma-to-germline inheritance should have been cited (Gorczynski and Steele, 1980, 1981). Further, a recent paper was overlooked in referencing. This demonstrated the soma-to-germline feedback phenomenon for regulatory double stranded RNA triggering RNA interference (RNAi) in C. elegans (Devanapally et al., 2015).

Gorczynski, R. M., and Steele, E. J. (1981). Simultaneous yet independent inheritance of somatically acquired tolerance to two distinct H-2 antigenic haplotype determinants in mice. Nature 289, 678-681. doi: 10.1038/ 289678a0

Kidd, M. J., Chen, Z., Wang, Y., Jackson, K. J., Zhang, L., Boyd, S. D., et al. (2012). The inference of phased haplotypes for the immunoglobulin $\mathrm{H}$ chain $\mathrm{V}$ region gene loci by analysis of VDJ rearrangements. J. Immunol. 188, 1333-1340. doi: 10.4049/jimmunol.1102097

Lindley, R. A. (2013). The importance of codon context for understanding the Iglike somatic hypermutation strand-biased patterns in TP53 mutations in breast cancer. Cancer Genet. 6, 222-226. doi: 10.1016/j.cancergen.2013.05.016

Lindley, R. A., and Steele, E. J. (2013). Critical analysis of strand-biased somatic mutation signatures in TP53 versus Ig genes, in genome-wide data and the etiology of cancer. ISRN Genomics 2013:921418. doi: 10.1155/2013/921418

Rassoulzadegan, M., Grandiean, V., Gounon, P., Vincent, S., Gillot, I., and Cuzin, F. (2006). RNA-mediated non-mendelian inheritance of an epigenetic change in the mouse. Nature 441, 469-474. doi: 10.1038/nature04674

Rothenfluh, H. S., Blanden, R. V., and Steele, E. J. (1995). Evolution of V Genes: DNA sequence structure of functional germ-line genes and pseudogenes. Immunogenetics 42, 159-171. doi: 10.1007/BF00191221

Rothenfluh, H. S., and Steele, E. J. (1993). Origin and maintenance of germ-line V-genes. Immunol. Cell Biol. 71, 227-232. doi: 10.1038/icb.1993.26

Sharma, U., Conine, C. C., Shea, J. M., Boskovic, A., Derr, A. G., Bing, X. Y., et al. (2016). Biogenesis and function of tRNA fragments during sperm maturation and fertilization in mammals. Science 351, 391-396. doi: 10.1126/ science.aad6780

Spadafora, C. (2008). Sperm-mediated "reverse" gene transfer: a role of reverse transcriptase in the generation of new genetic information. Hum. Reprod. 23, 735-740. doi: 10.1093/humrep/dem425

Steele, E. J. (1979). Somatic Selection and Adaptive Evolution: On the Inheritance of Acquired Characters. 1st Edn., Toronto:Williams-Wallace, 1979; 2nd Edn., Chicago, IL: University of Chicago Press. 1981.

Steele, E. J. (2009a). Lamarck and immunity: somatic and germline evolution of antibody genes. J. R. Soc. Western Australia 92, 437-446. Evolutionary Biology Symposium 2009. Available online at: http://www.rswa.org.au/publications/ Journal/92(4)/DARWIN\%20SYMP\%20-\%20EJ\%20STEELE\%20437-446.pdf 
Steele, E. J. (2009b). Mechanism of somatic hypermutation: critical analysis of strand biased mutation signatures at A:T and G:C base pairs. Mol. Immunol. 46, 305-320. doi: 10.1016/j.molimm.2008.10.021

Steele, E. J., and Pollard, J. W. (1987). Hypothesis: somatic hypermutation by gene conversion via the error prone DNA -to- RNA -to- DNA information loop. Mol. Immunol. 24, 667-673. doi: 10.1016/0161-5890(87)90049-6

Steele, E. J., and Lindley, R. A. (2010). Somatic mutation patterns in non-lymphoid cancers resemble the strand biased somatic hypermutation spectra of antibody genes. DNA Repair. 9, 600-603. doi: 10.1016/j.dnarep.2010.03.007

Steele, E. J., Lindley, R. A., and Blanden, R. V. (1998). Lamarck's Signature: How Retrogenes are Changing Darwin's Natural Selection Paradigm. Reading, MT: Addison-Wesley-Longman.

Steele, E. J., Lindley, R. A., Wen, J., and Weiler, G. F. (2006). Computational analyses show A-to-G mutations correlate with nascent mRNA hairpins at somatic hypermutation hotspots. DNA Repair 5, 1346-1363. doi: 10.1016/j.dnarep.2006.06.002

Steele, E. J., and Lloyd, S. S. (2015). Soma-to-germline feedback is implied by the extreme polymorphism at IGHV relative to MHC. Bioessays 37, 557-569. doi: 10.1002/bies.201400213

Storici, F., Bebenek, K., Kunkel, T. A., Gordenin, D. A., and Resnick, M. A. (2007). RNA-templated DNA repair Nature 447, 338-341. doi: 10.1038/nature05720

Temin, H. M., and Mizutuni, S. (1970). RNA-dependent 16/02/2016NA polymerase in virions of Rous Sarcoma Virus. Nature 226, 1211-1213. doi: $10.1038 / 2261211 \mathrm{a} 0$
Weiller, G. F., Rothenfluh, H. S., Zylstra, P., Gay, L., Averdunk, H., Steele, E. J., et al. (1998). Recombination signature of germline immunoglobulin variable genes. Immunol. Cell Biol. 76, 179-185.

Williamson, J. F., Steele, E. J., Lester, S., Kalai, O., Millman, J. A., Wolrige, L., et al. (2011). Genomic evolution in domestic cattle: ancestral haplotypes and healthy beef. Genomics 97, 304-312. doi: 10.1016/j.ygeno.2011.02.006

Zoraqi, G., and Spadafora, C. (1997). Integration of foreign DNA sequences into mouse sperm genome. DNA Cell Biol. 16, 291-300. doi: 10.1089/dna.1997.16.291

Zylstra, P., Franklin, A., Hassan, K. A. S., Powell, K. L., Steele, E. J., and Blanden, R. V. (2003). Molecular evolution of VHGAM3.8-related germline genes isolated from DBA, BALB/c, 129 and C57BL mouse strains and sublines. Immunogenetics 55, 182-188. doi: 10.1007/s00251-003-0565-x

Conflict of Interest Statement: The author declares that the research was conducted in the absence of any commercial or financial relationships that could be construed as a potential conflict of interest.

Copyright (c) 2016 Steele. This is an open-access article distributed under the terms of the Creative Commons Attribution License (CC BY). The use, distribution or reproduction in other forums is permitted, provided the original author(s) or licensor are credited and that the original publication in this journal is cited, in accordance with accepted academic practice. No use, distribution or reproduction is permitted which does not comply with these terms. 